\title{
REDE TEÓRICA ACERCA DA PRÁXIS DAS RELAÇÕES PÚBLICAS NO CONTEXTO DA SOCIEDADE MIDIATIZADA
}

\author{
ELISANGELA LASTA \\ UNIVERSIDADE FEDERAL DO RIO GRANDE DO SUL \\ PORTO ALEGRE, RIO GRANDE DO SUL, BRASIL \\ ELISANGELA.LASTA@UFRGS.BR
}




\section{REDE TEÓRICA ACERCA DA PRÁXIS DAS RELAÇÕES PÚBLICAS NO CONTEXTO DA SOCIEDADE MIDIATIZADA}

Resumo: O contexto da sociedade midiatizada implica no transformar acerca do fazer/existir/representar no espaço dos ambientes digitais por meio do saber dizer/publicizar. Consequentemente, conduz ao objetivo deste artigo de (re)pensar acerca de uma rede teórica para a práxis das relações públicas. Para alcançá-lo, fez-se uso dos achados obtidos a partir da pesquisa empírica em comunicação.

\section{INTRODUÇÃO}

Os pressupostos e argumentos são tecidos a partir da compreensão das relações públicas como função política, sendo delimitada como micropolítica, de acordo com Simões (1995; 2001). O processo de relações públicas apreendido no núcleo do sistema organização-públicos, isto é, o contexto organizacional considerado a partir das relações de poder entre organização e públicos. Contudo, o núcleo do sistema perpassado pelo processo de midiatização, logo considerado por meio do fazer/existir/representar dos atores individuais e coletivos constituídos nos ambientes digitais e suas respectivas operações discursivas construídas e disputadas (saber dizer/publicizar). Consequentemente, abrange os processos comunicacionais relativos aos fluxos de sentidos, postos em circulação, concernentes às e das organizações nos e pelos ambientes digitais.

Nossa justificativa centra-se nas conclusões obtidas com a tese: A práxis reflexiva das relações públicas na sociedade midiatizada: mediação estratégica comunicacional nos blogs corporativos, defendida pela autora, em 2015, pela Universidade Federal de Santa Maria (UFSM), com orientação da Dr. ${ }^{a}$ Eugenia M. R. Barichello. Com a tese constatamos a possibilidade para o desenvolvimento de uma rede teórica para apreendermos a práxis das relações públicas no contexto da sociedade midiatizada, sustentada na ética (legitimação), na política (relação) e na estética (processo comunicacional). Isto é, no explicar e no justificar relativos à existência da organização, suas ações e suas decisões a partir dos processos comunicacionais nos, e pelos, ambientes digitais, considerando o reconhecimento do outro. Assim, a práxis das relações públicas é raciocinada por meio da dinâmica sócio-técnicadiscursiva, isto é, a articulação das relações e/ou vínculos nos e pelos ambientes digitais, tendo sua materialização conferida através dos processos comunicacionais. 
Por conseguinte, neste artigo, objetivamos expor essa rede teórica considerando os achados obtidos a partir da pesquisa empírica em comunicação, ao considerar a íntima relação entre a teoria e o empírico. Para tanto, subdividimos em três partes: na primeira, abordamos a rede teórica da disciplina das relações públicas a partir de Simões (1995; 2001); na segunda, introduzimos o conceito de sociedade midiatizada com Sodré (2009) e Verón (2014), no contexto da comunicação organizacional com Baldissera (2001; 2009); Barichello (2009); na terceira, apresentamos a rede teórica acerca da práxis das relações públicas, no contexto da sociedade midiatizada, a partir de Lasta (2015).

\section{REDE TEÓRICA DA DISCIPLINA DE RELAÇões PÚBLICAS}

A proposta teórica de Simões (1995; 2001), acerca da disciplina de relações públicas, considera o processo (sistema) e o programa (atividade prática) e, estes, inscritos na ciência política. Ou seja, o processo das relações públicas, sob a perspectiva da função política e apreendido à micropolítica, é visualizado no núcleo do sistema social, no qual encontra-se a premissa organização-públicos como a figura 1, exposta a seguir, demonstra:

Figura 01: O processo das Relações Públicas

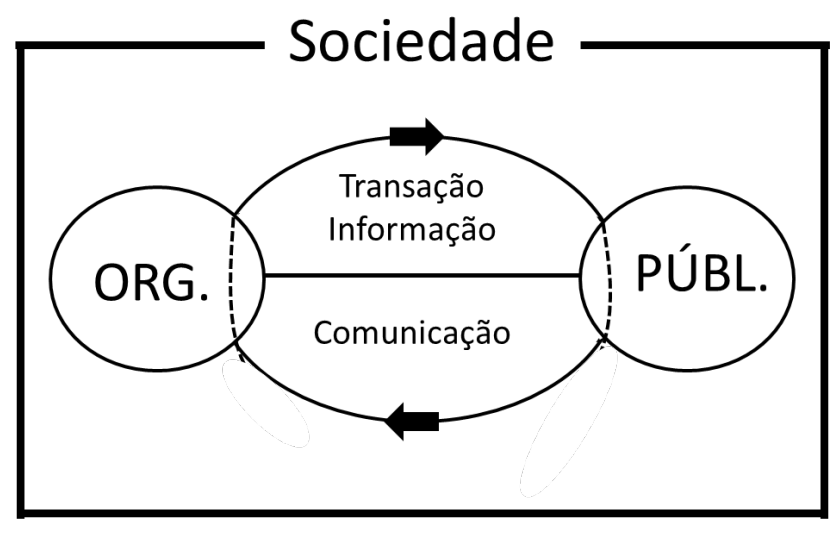

Fonte: Simões (1995, p. 53)

No núcleo desse sistema, encontramos os componentes materiais das relações públicas: a organização e os públicos, tendo a informação como o elemento ativador do processo e ao ser percebida pelos públicos dá continuidade ao processo. De acordo com Simões (1995; 2001), seu habitat encontra-se no jogo de interesses dos públicos com a organização e na possível iminência de conflitos. Já a comunicação toma a proporção de condição 
sine qua non para a ocorrência das trocas entre organização e públicos, enquanto que a transação seria a finalidade última ou até mesmo primeira, e ambos seriam para o teórico os "meios" para o alcance do objetivo principal: legitimação das ações organizacionais (SIMÕES, 1995) e/ou busca da cooperação no sistema organização-públicos (SIMÕES, 2001)1.

Considerando o núcleo deste sistema introduzimos a articulação entre o Quadro 1 - O arcabouço básico da rede teórica e o Quadro 2 - Rede teórica da disciplina de Relações Públicas, desenvolvidos por Simões (1995; 2001), para compreendermos acerca da práxis das relações públicas. No entanto, como o próprio autor salienta, esses quadros são datados, ou seja, são de uma determinada fase do desenvolvimento da ciência das relações públicas e seu valor está na possibilidade de gerar outros conhecimentos críticos a partir deles. No Quadro 1 - O arcabouço básico da rede teórica (SIMÕES, 1995), há a seguinte articulação teórica:

Quadro 01: O arcabouço básico da rede teórica

\begin{tabular}{|l|l|}
\hline $\begin{array}{l}\text { a) Definição conceitual: } \\
\text { (o que são Relações Públicas?) }\end{array}$ & $\begin{array}{l}\text { Como ciência, Relações Públicas abarca o conheci- } \\
\text { mento científico que explica, prevê e controla o ex- } \\
\text { ercício de poder no sistema organização-públicos. } \\
\text { Como atividade, Relações Públicas é o exercício da } \\
\text { administração da função (subsistema) política orga- } \\
\text { nizacional, enfocado através do processo de comuni- } \\
\text { cação da organização com seus públicos. }\end{array}$ \\
\hline $\begin{array}{l}\text { b) Definição operacional: } \\
\text { (como se exerce esta atividade?) }\end{array}$ & $\begin{array}{l}\text { a) analisando tendências; b) prevendo consequên- } \\
\text { cias; c) assessorando o poder de decisão; d) imple- } \\
\text { mentando programas planejados de comunicação. }\end{array}$ \\
\hline $\begin{array}{l}\text { c) Objetos da ciência e da ativi- } \\
\text { dade: (Cientificamente, quais } \\
\text { são seus objetos de estudo e } \\
\text { manejo?) }\end{array}$ & $\begin{array}{l}\text { Material: A organização e os públicos. } \\
\text { Formal: O conflito no sistema organização-públicos, } \\
\text { ou dialeticamente, a compreensão mútua. }\end{array}$ \\
\hline $\begin{array}{l}\text { d) Causa da existência da ativi- } \\
\text { dade: } \\
\text { (Por que esta atividade foi iden- } \\
\text { tificada e considerada útil pela } \\
\text { sociedade?) }\end{array}$ & $\begin{array}{l}\text { O conflito eminente no sistema organização-públi- } \\
\text { cos. }\end{array}$ \\
\hline
\end{tabular}

1 Na revisão (SIMÕES, 2001) da obra Simões (1995) esse objetivo principal da atividade é alterado, anteriormente era a legitimação das ações organizacionais agora passa a ser a busca da cooperação no sistema organização-públicos e a legitimação passou para a esfera da ética. 


\begin{tabular}{|c|c|}
\hline $\begin{array}{l}\text { e) Níveis do problema no sistema } \\
\text { organização-públicos: (Qual é a } \\
\text { sintomatologia?) }\end{array}$ & $\begin{array}{l}\text { Um processo que vai desde a integração dos interess- } \\
\text { es até a convulsão social. }\end{array}$ \\
\hline $\begin{array}{l}\text { f) O aspecto político: } \\
\text { (Por que política e não comuni- } \\
\text { cação?) }\end{array}$ & $\begin{array}{l}\text { A relação é política. O instrumento é a comunicação. } \\
\text { Dois lados da mesma moeda. }\end{array}$ \\
\hline $\begin{array}{l}\text { g) A matéria-prima: (Qual o ele- } \\
\text { mento que gera, evita e resolve } \\
\text { conflitos?) }\end{array}$ & A informação. \\
\hline $\begin{array}{l}\text { h) Os instrumentos: } \\
\text { (Como se busca e envia infor- } \\
\text { mação?) }\end{array}$ & $\begin{array}{l}\text { Antes de tudo, através de políticas e normas admin- } \\
\text { istrativas justas e produto e serviço com qualidade. } \\
\text { Depois, através de todo e qualquer meio, existente } \\
\text { ou a ser criado que leve mensagens da organização a } \\
\text { seus públicos e vice-versa. }\end{array}$ \\
\hline $\begin{array}{l}\text { i) O objetivo: } \\
\text { (A que visa a função e a ativi- } \\
\text { dade?) }\end{array}$ & Legitimar as decisões organizacionais. \\
\hline $\begin{array}{l}\text { j) A finalidade: } \\
\text { (Para que legitimar?) }\end{array}$ & $\begin{array}{l}\text { Facilitar as transações com os diversos públicos, além } \\
\text { dos clientes, e mantê-los fiéis e multiplicadores. }\end{array}$ \\
\hline $\begin{array}{l}\text { k) A ética: } \\
\text { (É ética a atividade de Relações } \\
\text { Públicas?) }\end{array}$ & $\begin{array}{l}\text { A atividade de Relações Públicas em si é ética, pois } \\
\text { é útil para a sociedade. Os problemas éticos são ger- } \\
\text { ados pelos profissionais como em qualquer outra } \\
\text { atividade. Todavia, a essência da ética é intrínseca ao } \\
\text { processo de legitimação. }\end{array}$ \\
\hline $\begin{array}{l}\text { l) A estética: } \\
\text { (Qual é o beneficio para a socie- } \\
\text { dade?) }\end{array}$ & $\begin{array}{l}\text { As Relações Públicas buscam a utopia de uma socie- } \\
\text { dade mais harmônica e "elegante". }\end{array}$ \\
\hline
\end{tabular}

Fonte: Simões (1995, p. 42)

Já no Quadro 2 - Rede teórica da disciplina de Relações Públicas (SIMÕES, 2001) -, pode ser visualizada a seguinte arquitetura teórica:

Quadro 02: Rede teórica da disciplina de Relações Públicas

\begin{tabular}{|c|c|c|}
\hline $\begin{array}{l}\text { Por que existe a atividade } \\
\text { de Relações Públicas? }\end{array}$ & CAUSA & a iminência do conflito no sistema \\
\hline $\begin{array}{l}\text { O que é a atividade de } \\
\text { Relações Públicas? }\end{array}$ & $\begin{array}{l}\text { D E F I N I ÇÃ O } \\
\text { CONCEITUAL } \\
\end{array}$ & a gestão da função organizacional política \\
\hline $\begin{array}{l}\text { A que visa a atividade de } \\
\text { Relações Públicas? }\end{array}$ & OBJETIVO & $\begin{array}{l}\text { à cooperação no sistema para a con- } \\
\text { secução da missão da organização }\end{array}$ \\
\hline $\begin{array}{l}\text { Qual o corpo de análise e de } \\
\text { intervenção da atividade de } \\
\text { Relações Públicas? }\end{array}$ & $\begin{array}{l}\text { OBJETO } \\
\text { Material } \\
\text { OBJETO } \\
\text { Formal }\end{array}$ & $\begin{array}{l}\text { sistema: organização-públicos "anatomia } \\
\text { e fisiologia" } \\
\text { conflito/cooperação "sintomatologia" }\end{array}$ \\
\hline
\end{tabular}




\begin{tabular}{|c|c|c|}
\hline $\begin{array}{l}\text { Quais os participantes do } \\
\text { sistema? }\end{array}$ & $\begin{array}{l}\text { COMPONEN- } \\
\text { TES }\end{array}$ & organização - organização \\
\hline $\begin{array}{l}\text { Quais as esferas do relacio- } \\
\text { namento? }\end{array}$ & DIMENSÕES & $\begin{array}{l}\text { cultural, econômica, política, ideológica, } \\
\text { histórica, jurídica e filosófica }\end{array}$ \\
\hline $\begin{array}{l}\text { Quais as fases da dialética } \\
\text { cooperação/conflito? }\end{array}$ & ETAPAS & $\begin{array}{l}\text { satisfação, insatisfação, boato, coligações, } \\
\text { pressão, conflito, crise, troca de poder, ar- } \\
\text { bitragem, convulsão social }\end{array}$ \\
\hline $\begin{array}{l}\text { Como é exercida a atividade } \\
\text { de Relações Públicas? }\end{array}$ & $\begin{array}{l}\text { D E F I N I Ç ÃO } \\
\text { OPERACIONAL }\end{array}$ & $\begin{array}{l}\text { diagnosticando o sistema; prognostican- } \\
\text { do o futuro do sistema; assessorando nas } \\
\text { politicas organizacionais; e implementan- } \\
\text { do programas de comunicação }\end{array}$ \\
\hline $\begin{array}{l}\text { Com que variáveis a ativi- } \\
\text { dade de Relações Públicas } \\
\text { intervém no processo? }\end{array}$ & $\begin{array}{l}\text { BASES DE } \\
\text { PODER }\end{array}$ & $\begin{array}{l}\text { ação: legal, legitima, recompensa } \\
\text { comunicação: informar, persuadir, nego- } \\
\text { ciar }\end{array}$ \\
\hline $\begin{array}{l}\text { Qual o elemento comum às } \\
\text { bases de poder que organi- } \\
\text { zam o processo? }\end{array}$ & $\begin{array}{l}\text { MATÉRIA-PRI- } \\
\text { MA }\end{array}$ & informação: redução da incerteza \\
\hline $\begin{array}{l}\text { De que maneira são envia- } \\
\text { das as mensagens? }\end{array}$ & $\begin{array}{l}\text { T É C N I C A S } \\
\text { MIDIÁTICAS } \\
\end{array}$ & de entrada, de saída e mistas \\
\hline $\begin{array}{l}\text { Que fatores justificam a } \\
\text { existência da atividade de } \\
\text { Relações Públicas? }\end{array}$ & $\begin{array}{l}\text { BASES FI- } \\
\text { LOSÓFICAS }\end{array}$ & $\begin{array}{l}\text { ética: a legitimação da ação organizacio- } \\
\text { nal } \\
\text { estética: as ações bem pensadas, projeta- } \\
\text { das e realizadas }\end{array}$ \\
\hline
\end{tabular}

Fonte: Simões (2001, p. 49)

No entrecruzamento dos quadros 1 e 2 nos deparamos com a seguinte disposição teórica: como a ciência das relações públicas abarca o conhecimento entre a ciência (teoria) com a atividade (prática) permite que se ponha diante à práxis. Uma vez que, a conceituação de práxis, de acordo com Vázquez (1968), trata-se da íntima unidade entre teoria e prática. Já a gerência da atividade das relações públicas, definida como gestão da função organizacional política, é gerenciada por intermédio do profissional de relações públicas, a partir de quatro práticas ordenadas logicamente:

1. Diagnosticar o sistema organização-públicos e, posteriori, concluir a análise acerca de como se encontra a organização perante os interesses dos públicos;

2. Prognosticar a propósito do que poderá vir a ocorrer no sistema organização-públicos, busca prever o futuro do sistema, baseado nas conclusões do diagnóstico;

3. Assessorar as lideranças da organização em relação às políticas ad- 
ministrativas, considerando o diagnóstico e o prognóstico;

4. E, implementar programas planejados de comunicação, que são definidos após a operacionalização das três prática anteriores.

Essas são as quatro práticas que definem o operacional da atividade, isto é, que explicam o que faz a atividade prática das relações públicas. Todavia, para que elas possam ocorrer, é preciso o conhecimento teórico acerca do conjunto de conceitos, definições e princípios (pesquisa pura/ciência pura) e conhecimentos tecnológicos relativos à gama de conhecimentos científicos que geram as técnicas (pesquisa aplicada/ciência aplicada). Pois, "se o know-how é adquirido e aperfeiçoado pelo labutar diário, as técnicas necessitam da tecnologia que implica, antes, teoria" (SIMÕES, 2001, p. 40). Ou seja, o duplo movimento íntimo entre teoria e prática.

Já, em relação ao objetivo da função e da atividade das relações públicas, cabe relembrar que a angular de legitimar as decisões e as ações organizacionais, que consta na obra de Simões publicada em 1995, se deslocasse para a consecução de sua missão organizacional na obra de 2001. Enquanto que, a função política se ocupa da relação de poder entre a organização e seus agentes de influência e contém as ações correlacionadas com o processo do exercício de poder/comunicação interna e externa à organização. Dessa forma, a legitimação ancora na ética das ações da organização e seus princípios que, integrados, garantem à profissão de relações públicas sua razão de existir para a sociedade. Logo, trata-se da essência do processo de comunicação e, este, da aparência da atividade, uma vez que, a essência da atividade está nas relações de poder.

O exposto reflete, em ética e estética, nos fatores que justificam a existência da atividade das relações públicas perante a sociedade, pois a ética está sustentada na busca da legitimação das ações da organização e, esta, no discurso, na informação - que para Simões (1995; 2001), é matéria-prima ou primária da atividade de relações públicas a ser transformada pelo profissional - e na liberdade de decisão articulada à estética, ou seja, no plano das ações projetadas e executadas. Na estética, encontramos a comunicação, o cerne da práxis das relações públicas, que está atrelado à sua razão de existir e à sociedade que imputa reflexão sobre ela. A teoria refere-se à filosofia que compreende a ação humana por meio de sua análise, visto que toda ação humana implica em ética e estética. Desse modo, a relação social da organização pode caracterizar-se como: a) ética, se cumprir com suas ações organizacionais; e b) estética, se suas ações estiverem em consonância com 
seus discursos.

Essa conjuntura está inserida no processo (sistema organização-públicos), que equivale à dinâmica do fenômeno e as suas variáveis. Entende-se que, para conhecer o processo exige-se a análise e, para implantar o programa, requer-se que se opte por abordagens e técnicas, as quais Simões (2001) delimitou ao programa da micropolítica. Este se ocupa das relações de poder entre o sistema organização-públicos, enquanto que suas bases estratégicas são sustentadas para lidar com grupos de interesses e reestruturar as circunstâncias.

Por meio dessa estrutura teórica, buscaremos derivar visando à compreensão da práxis das relações públicas, atrelada ao duplo movimento entre teoria e atividade prática, sustentadas no contexto da sociedade midiatizada.

\section{COMUNICAÇÃO ORGANIZACIONAL NO CONTEXTO DA SOCIEDADE MIDIATIZADA}

O entendimento de realidade social (sociedade midiatizada) neste estudo refere-se ao conjunto de múltiplos atores sociais que criam seus espaços nos quais regulam seus tempos, no âmbito tecnológico. Esse recorte de realidade nos insere no mundo dos objetos, das linguagens, dos símbolos e dos significados, no qual os sujeitos vivem e constroem suas realidades por meio da mediação tecnológica; ou seja, no processo que envolve os múltiplos atores agenciados com múltiplos ambientes digitais. Consequentemente, os atores, neste contexto, são reconhecidos como construtores de suas realidades por meio de mediações tecnológicas, pois são observadores (reconhecedores) e construtores de estruturas e sistemas (VIZER, 2011).

Trata-se da dinâmica do "eu", percebido pelo outro, isto é, um "eu" consciente de que é observado, contudo também está observando e, implicará em relações de interdependência mútua. Significa que a realidade social é perpassada também na organização por um mútuo desejar, no qual cada um deseja ser reconhecido. Este desejo dirige-se ao outro e no reconhecimento do seu valor, que ocorre por meio do movimento de diferenciação e de semelhança. Pois, se há o "eu" e o outro, apreendido pela diferenciação e aproximação, há o indivíduo concretamente em uma relação. Uma vez que, este "eu" só existe se reconhecido/legitimado pelo outro, consequentemente, requererá que este tenha sua subjetividade exteriorizada; logo, implicará na exposição de si ao "olhar" do outro, observação conquistada e 
demandada, visando ter sua visibilidade atestada (BRUNO, 2004). No entanto, também implicará no "olhar" dos buscadores, que hoje ocorre pela utilização das palavras-chaves e dos links (FELIPINI, 2010; OLIVEIRA, 2010). Mas, se considerarmos o desenvolvimento da Web semântica envolverá o ator reconhecido como entidade e conteúdo, a partir dos significados e sentidos.

Conforme adverte Sodré (2009), a sociedade midiatizada como ethos (em grego) designa sentido de habitar como extensão e conexões; entretanto, também designa "caráter", a imagem moral do orador construída pelo seu discurso público. Esse processo torna-se responsável por construir a realidade social na perspectiva da sociedade midiatizada, uma vez que, considera o agenciamento do ator ao ambiente digital e, a partir dele, a produção de sentido e ou formações de vínculos pelo discurso. Assim, além de se "falar", se reconhece o valor social do outro, logo reordena o social mediante os conteúdos midiáticos (modalidades do discurso por meio de elos intertextuais) e os significados.

Essa exteriorização da subjetividade se dá por meio dos processos comunicacionais, atrelados com e nos ambientes digitais, que têm códigos, estruturas, regras e condutas particulares. Consequentemente, trata-se do processo de midiatização acionado a partir das práticas tecnológicas do discurso, implicado em retórica e, esta, em elocução, linguagem, discurso (níveis de operações discursivas) (SODRÉ, 2009), que impactam na comunicação organizacional provocando interpretações e reflexões acerca da dinâmica do agir nesse contexto. Pois, as organizações também se constituem no seu fazer e existir nos e pelos ambientes digitais, logo nos encaminha à comunicação organizacional midiatizada (BARICHELLO, 2009). Isto é, alteridade posta em e na relação por meio dos processos comunicacionais oficiais/formais e não-oficiais/informais (BALDISSERA, 2009).

Portanto, conjuntura dos sentidos (construídos, apropriados e reapropriados) postos em circulação relativos às, e das, organizações. Pois, esses múltiplos atores selecionam, combinam e avaliam os recursos, do mundo social e material, e negociam os significados e as ações nos e pelos ambientes digitais. Assim desejam se fazer visíveis/legitimados, isto é, que o olhar do outro lhe "reconheça e lhe atribua sentido, existência" (BRUNO, 2004, p. 118). Para tanto, encaram o processo de legitimação que é instaurado, na exteriorização da subjetividade, por meio do explicar e do justificar acerca das realidades construídas (BERGER; LUCKMANN, 1997). Tanto o processo de visibilidade como o de legitimidade são instaurados pelos múltiplos ato- 
res nos seus respectivos ambientes digitais, porém trata-se de um vir a ser, pois vão além do olhar do outro e se inserem na esfera do reconhecimento.

Como salienta Verón (2014), o processo de midiatização emboca em três consequências: $\left.1^{\mathrm{a}}\right)$ na autonomia dos emissores e receptores dos signos materializados; $2^{\mathrm{a}}$ ) na persistência no tempo e espaço desses signos materializados; e $3^{\mathrm{a}}$ ) no corpo de normas sociais, que definem as formas de acesso aos signos e, estes últimos, como autônomos e persistentes no espaço/tempo. Por conseguinte, enunciador, discurso e destinatário, localizam-se no espaço/tempo homogêneo.

Os ambientes digitais tomam significância ao serem apropriados pelos múltiplos atores, ao passo que estes fazem seu uso, consequentemente o institucionalizam e inserem no fenômeno da midiatização. Pois, como indicou Sodré (2009), os ambientes digitais são uma espécie de "prótese"; isto é, uma extensão especular, na qual o ator "habita" e pode "entrar" e "mover-se" por meio dos códigos e das regras próprias a cada ambiente. Portanto, as vinculações pressupõem inserção social do ator até a deliberação; ou seja, seria mais do que processo de interação, por requerer o sentido ético-político do bem-comum. Logo, nos encaminha à refiguração da experiência das organizações em seus relacionamentos, na perspectiva do fenômeno da midiatização e de modo crítico.

Essas discussões convergem para a área das relações públicas, que de acordo com Kunsch (2014), ao longo do tempo foi ancorada nas práticas do mercado profissional. E, como afere Moura (2008), teve seu currículo mínimo estabelecido por meio do campo da comunicação e seu ensino reconhecido nas e pelas práticas profissionais. Em consequência, no que se refere à literatura e às práticas relativas à área, para Baldissera (2009), Barichello (2008) e Kunsch (2009), estas ainda são difundidas a partir do processo profissional, que organiza as comunicações da organização e as envia ao campo dos media e/ou aos públicos, considerando-os como agentes passivos no processo. Porém, como afirma Sodré (2009), dentro da realidade da sociedade midiatizada, ocorre o transformar da vida, que "obriga" o indivíduo a “obrigar-se" para com o outro. Essa dinâmica, que envolve a exteriorização de si para outrem, implica em considerar a alteridade por meio dos conteúdos.

A organização, neste contexto, passa a "habitar" os ambientes digitais e a se fazer e existir neles, e por meio deles, a partir dos processos comunicacionais. Portanto, como expõe Barichello (2009), a mediação se dá nos 
ambientes digitais, por meio dos quais as organizações buscam se explicar e se justificar frente à sociedade. Esse procedimento requer a criação de outros fluxos de comunicação e de outros formatos organizacionais; isto é, outras formas de mediação e interlocução para com seus públicos. Conforme afere Baldissera (2009), as organizações atualizam-se nas inter-relações, ou seja, no acontecer, pois as relações de comunicação se dão por meio dos sentidos construídos e disputados por múltiplos atores. E, nesta conjuntura, para Baldissera (2001), o profissional de relações públicas passa a exercer sua atividade prática articulando recursos comunicacionais sob os objetivos de: garantir a circulação de informações e significados para institucionalizar (comunicar e fazer reconhecer) a organização como referência.

Foi possível, também, observar com a tese que, na sociedade midiatizada, as organizações ${ }^{2}$ se constituíram por meio dos agenciamentos com ambientes digitais e, subsequentemente, construíram relações. Na primeira dimensão houve o fazer/existir/representar das organizações; já na segunda, o saber dizer/publicizar pelo processo sócio-técnico-discursivo, como os seguintes dados teórico-empíricos ${ }^{3}$ evidenciam:

$\left.1^{\circ}\right) \mathrm{O}$ agenciamento dos atores das organizações, que se refere à descrição das ações das organizações nos seus ambientes digitais (o seu fazer/ existir/representar):

a) a prática relativa à materialização da retórica [...] por meio dos links contextuais de referência a outrem esteve presente no período analisado em $13 \%$ das postagens. Consequentemente, nos

2 Campo de estudo composto pelas organizações: Telefônica Brasil S.A; Magazine Luiza S.A.; Guararapes Confecções S.A.; Têxtil Renauxview S.A.; Ampla Energia e Serviços S.A.; Light S.A.; Portobello S.A.; Petróleo Brasileiro S.A. Petrobras; Cia Energética de Minas Gerais; Anhanguera.

Educacional Participações S.A; Natura Cosméticos S.A.; Dohler S.A.; Duke Energy Int. Ger. Paranapanema S.A.; Gol Linhas Aéreas Inteligentes S.A; e Cyrela Brazil Realty S.A. Empreend. e Part

3 Obtidos a partir da pesquisa empírica em comunicação que foi operacionalizada por um dispositivo teórico-metodológico que se refere: ao nível relacional que se ocupou de descrever o agenciamento do ator com o ambiente digital, a partir do método observação encoberta e não participativa (JOHNSON, 2010); ao nível vinculativo, que se ocupou de montar essa lógica, considerando a estrutura e os códigos próprios do ambiente digital, por meio do método da análise estrutural das redes sociais (LEMIEUX; QUIMET, 2004); e ao nível-crítico cognitivo que se ocupou da análise comparada, a partir da análise dos enunciados presentes no discurso (PERUZZOLO, 2004), que conduziu à intersecção dessas três análises. 
remete a especulação de que esses dados representam uma prática ainda consideravelmente tímida [...]; b) os links contextuais de referência a outrem com porcentagem expressiva encaminharam para Ator/Espaço em $71,73 \%$ do corpus de pesquisa, seguidos de $28,26 \%$ referentes a Ator/Espaço/Texto. Logo, estes dados nos permitem aferir que há um espaço a ser preenchido em relação a possíveis estratégias comunicacionais que considerem não somente os atores e espaços, mas também os textos; c) as ambiências com as quais ocorreram mais relações foram os sites com $76,32 \%$, enciclopédia digital com $14,13 \%$, seguidas de $7,77 \%$ com os blogs. Esses dados demonstram que as relações estabelecidas se deram com ambiências que se constituem abertas na estrutura da Web, consequentemente suas visibilidades e legitimidades se encontram intrínsecas com os 'olhares' de 'outrem' [...] e dos serviços de busca [...]; d) as relações com os demais múltiplos atores sociais se deram principalmente com os atores das instituições não midiáticas com $45,58 \%$, isto é, nos indicam que há uma tendência considerável em manter relações com seus pares; a seguir encontram-se os atores coletivos com $23,32 \%$ que demonstram as relações existentes entre atores das instituições não midiáticas do campo de estudo com atores coletivos [...]; após surgem os atores individuais com 13,78\% [...]; na sequencia os atores das instituições midiáticas com $12 \%$, a princípio, demonstra que os atores das instituições não midiáticas do campo de estudo estão se apropriando/ utilizando destes espaços para construírem relações diretas com cada um dos múltiplos atores [...]; e, por último, com 5,3\% os atores do Estado (LASTA, 2015, p. 173).

$2^{\circ}$ ) A montagem da lógica na construção das redes sociais, isto é, a prática da constituição de relações e/ou vínculos pelas organizações nos ambientes digitais (considerando a estrutura e os códigos próprios destes):

[...] não se trata apenas de quantidade de relações, mas também da qualidade das relações, ou seja, relações contínuas com os mesmos múltiplos atores, relações de exclusividade e relações com atores com representatividade na rede. Este levantamento influencia no posicionamento dos atores na matriz social por meio da mediação estratégica comunicacional [...]. Consequentemente, requer dos atores das instituições não midiáticas do campo de estudo considerar os múltiplos atores com posicionamento relevante na rede, entretanto que estejam relacionados com eles e possuam conteúdos relacionados com os seus, para posteriori estabelecer relacionamentos contínuos visando à reciprocidade [...] (LASTA, 2015, p. 188). 
$3^{\circ}$ ) A organização do discurso, que se refere ao seu o saber dizer/publicizar:

\begin{abstract}
1) ancoraram seu discurso em outrem, ao dizer de outrem e/ou em elementos reconhecidos pelos enunciatários. Passam a negociar os sentidos com os interlocutores; 2) fazem uso da figura discursiva do enunciador pedagógico que pré-ordena o discurso visando guiar o enunciatário. Seguem a lógica de ordenação de seus sentidos e dos interlocutores; 3 ) interseccionam entre os efeitos de enunciação de objetividade e subjetividade, em sua grande maioria, através das articulações entre os temas núcleo apoiados em periféricos. Lógicas e operações passam por transformações de protocolo enunciativos tanto do campo dos mídia como das instituições não midiáticas; 4) por meio do efeito de enunciação de objetividade, com uma percentagem menor, através da disseminação dos temas núcleo; 5) a partir efeito de enunciação de subjetividade, com uma percentagem pequena, através tema núcleo ancorado no discurso de outrem (LASTA, 2015, p. 224).
\end{abstract}

$\left.4^{\circ}\right)$ A redescrição da existência das organizações em função do contexto da sociedade midiatizada, que rege o seu modo de ser na tecnologia, isto é, se dá por meio da materialização da retórica somada as relações intersubjetivas (processo sócio-técnico-discursivo):

1) processo comunicacional de referencialidade em posição central para o estabelecimento da estratégia; 2) discurso elaborado e/ou reelaborado através da ação primeira de inserir e/ou ancorar o outro como ator/espaço/conteúdo no seu discurso; 3) transformação nos protocolos enunciativos do campo da comunicação organizacional ao promoverem a produção dos seus sentidos ('falar' de si mesmo) e dos sentidos dos seus interlocutores ('falar' do outro e com o outro); 4) negociação dos sentidos a partir dos seus espaços/media; 5) prática referencial que exerce o reconhecimento de outrem e constrói redes de relações; 6) comunicação organizacional no contexto da midiatização amplia-se para além dos processos comunicacionais centrados nos próprios AINMCE e, assim passa a reconhecer a alteridade no processo ao ceder 'espaço' ao outro (LASTA, 2015, p. 224).

A partir destes dados empíricos, interconectados com a base teórica, entende-se que as organizações do campo de estudo promovem em seu ambiente digital a produção de seus sentidos ao "falar" de si mesmo como também dos sentidos de seus interlocutores ao "falar" do outro e com o 
outro. Logo, passam a negociar os sentidos nos e pelos seus espaços. Outra questão interessante encontra-se nos protocolos enunciativos relativos à relação do sujeito com sua fala ao que se refere ao exame das relações do sujeito de enunciação com seu discurso e das relações argumentativas entre enunciador e enunciatário. Ou seja, do lugar dos sujeitos no discurso, precisamente nos efeitos de enunciação, que de acordo com Peruzzolo (2004), diz respeito às projeções do sujeito de enunciação no seu discurso, por meio da modalidade do dizer, operada na pessoa verbal e no tempo, que implica em dois efeitos: efeito de enunciação de subjetividade, quando o enunciador se coloca perto do dito (efeito de aproximação); efeito de objetividade, quando este se coloca longe do dito (efeito de afastamento).

Estes dois efeitos indicaram que a posição que os sujeitos de enunciação (organizações) deram para si mesmas no discurso foi ora perto do dito, ora longe; isto é, os dois efeitos foram interseccionados. Consequentemente, reafirma que as lógicas e operações do campo dos mídia (efeito de objetividade) são apropriadas pelas organizações (BARICHELLO; LASTA, 2010). Entretanto, também são reapropriadas, uma vez que, ultrapassaram o efeito de objetividade ao serem cruzadas com os protocolos enunciativos atribuídos ao efeito de enunciação de subjetividade - reconhecido na área das relações públicas tradicionalmente a partir da postura da ordenação dos sentidos organizacionais, isto é, o "falar" sobre si mesmo e se responsabilizar por esse dito.

Assim, cada parte do componente da sociedade - aqui compreendido pelo sistema organização-públicos -, implica em relações de poder no sistema social (dimensão política) e nas relações sociais que são políticas. Com base nessa situação, a atividade das relações públicas intervém no processo por meio da variável: processo comunicacional (fenômeno constituído pela tecnologia da retórica) - base de poder exercidas no sistema. Portanto, a práxis das relações públicas no contexto da sociedade midiatizada envolve a interpretação crítica nas relações/vínculos; consequentemente, o (re)pensar de estratégias de se comunicar, pois a alteridade é reconhecida como ator nos processos comunicacionais.

\section{REDE TEÓRICA ACERCA DA PRÁXIS DAS RELAÇÕES PÚBLICAS NO CONTEXTO DA SOCIEDADE MIDIATIZADA}

A discussão acerca dos elementos do Quadro 1 - O arcabouço básico da rede teórica (SIMÕES, 1995), combinados com o Quadro 2 - Rede teórica da 
disciplina de Relações Públicas (SIMÕES, 2001), comportou a rearticulação com o contexto da comunicação organizacional na sociedade midiatizada, apreendido por meio dos dados teórico-empíricos e, assim, nos permitiu a introdução do Quadro 3, exposto a seguir:

\begin{tabular}{|c|c|}
\hline Elementos & $\begin{array}{l}\text { Práxis das Relações Públicas na sociedade midiatiza- } \\
\text { da }\end{array}$ \\
\hline - Definição operacional & $\begin{array}{l}\text { - Diagnosticar -> Pesquisar o sistema; } \\
\text { - Prognosticar -> Prever sobre o sistema; } \\
\text { - Assessorar -> Ter alternativas para/no sistema; } \\
\text { - Implementar -> Planejar e executar sobre/no siste- } \\
\text { ma. }\end{array}$ \\
\hline $\begin{array}{l}\text { - Objetos da ciência e da ativi- } \\
\text { dade/corpo de análise e de inter- } \\
\text { venção da atividade: }\end{array}$ & $\begin{array}{l}\text { - Material: sistema organização-públicos no/pelo am- } \\
\text { biente digital; } \\
\text { - Formal: conflito/cooperação/negociação. }\end{array}$ \\
\hline $\begin{array}{l}\text { - Causa da existência da ativi- } \\
\text { dade: }\end{array}$ & - Iminência do conflito e/ou cooperação no sistema. \\
\hline - Aspecto político: & $\begin{array}{l}\text { - Ético-político-estético (legitimação-relação/víncu- } \\
\text { lo-processo comunicacional (sócio-técnico-discur- } \\
\text { sivo)). }\end{array}$ \\
\hline $\begin{array}{l}\text { - Matéria-prima (elemento co- } \\
\text { mum às bases de poder que or- } \\
\text { ganiza o processo): }\end{array}$ & - Dados, informações, conhecimentos. \\
\hline $\begin{array}{l}\text { - O lócus da função e da ativi- } \\
\text { dade: }\end{array}$ & $\begin{array}{l}\text { - Nos processos comunicacionais (sócio-técnico-dis- } \\
\text { cursivo) por meio dos ambientes digitais. }\end{array}$ \\
\hline $\begin{array}{l}\text { - Objetivo da função e da ativi- } \\
\text { dade: }\end{array}$ & $\begin{array}{l}\text { - Explicar/justificar a existência; as decisões; e as ações } \\
\text { da organização através da negociação nos processos } \\
\text { comunicacionais, reconhecendo o outro e, visando } \\
\text { institucionalizar (comunicar e fazer reconhecer) a or- } \\
\text { ganização como referência. }\end{array}$ \\
\hline $\begin{array}{l}\text { - Bases filosóficas (que fatores } \\
\text { justificam a existência da ativi- } \\
\text { dade): }\end{array}$ & $\begin{array}{l}\text { - Ética + estética (a legitimação através dos processos } \\
\text { comunicacionais nos ambientes digitais). }\end{array}$ \\
\hline
\end{tabular}

Fonte: Elaborado pela autora

Definição operacional da atividade de relações públicas: ao considerar essas observações no "fazer" de relações públicas, isto é, na sua prática por meio da informação, têm-se as seguintes premissas: $1^{\circ}$ ) Diagnosticar: por meio da prática da pesquisa, buscar dados e transformá-los em informação. Significa conhecer a realidade concernente ao sistema (organização-públicos), na qual se pretende atuar e refletir (permite que ocorra a segunda 
prática); $2^{\circ}$ ) Prognosticar: por meio do estudo das dinâmicas no processo comunicacional; ou seja, após os dados terem sido transformados em informações e, estas, em conhecimento. Significa que, a partir do conhecimento da realidade do sistema poderá fazer projeções, pois terá conhecimento acerca dos objetos, meios e instrumentos; $3^{\circ}$ ) Assessorar: por meio da exposição dos dados, informações e conhecimentos, assessorar por meio de alternativas, ou seja, modificar, agir e atuar sobre a matéria-prima (dados, informações, conhecimentos); $4^{\circ}$ ) Implementar: por meio dos dados e informações colocar o conhecimento extraído dos processos comunicacionais nos ambientes digitais, a fim de aproximar as partes do sistema e/ou explicar/justificar a organização, suas ações e decisões.

Objetos da ciência e atividade, "corpo" de análise e intervenção da atividade: a partir da contextualização da sociedade midiatizada os sujeitos encontram-se inseridos nos objetos da ciência e da atividade; isto é, nos "corpos" de análise e de intervenção da atividade das relações públicas e estão divididos em: a) Objeto material: se refere ao sistema organização-públicos, considerando a estrutura, componentes e dinamicidade, ou seja, as distintas articulações no fazer/existir/representar e dizer/publicizar nos e pelos ambientes digitais; b) Objeto formal: concernente ao conflito e/ou a cooperação, ambos relativos ao processo do sistema; isto é, aos constructos dos múltiplos atores acerca de suas realidades com a tecnologia, enquanto observadores (reconhecedores) e construtores de estruturas e sistemas. Portanto, encaminha-se às esferas referentes às dimensões dos relacionamentos/vínculos da organização com seus públicos; ou seja, designa os aspectos específicos da relação/vínculo entre eles. Trata-se de um sistema social, logo, de um sistema em sociedade que, por sua vez, origina relações de interdependência mútua, pois a alteridade é reconhecida e posta na/em relação.

Causa da existência da atividade de relações públicas na conjuntura da sociedade midiatizada: encontra-se na iminência do conflito e da cooperação no sistema, pois os atores encontram-se em relações de mútua interdependência - o eu e o outro -, por meio do movimento da diferenciação e aproximação. Isso decorre em razão de, para virem a ser visíveis e legitimados, dependem do olhar do outro, que este Ihe reconheça como também Ihe atribua sentido e existência. Consequentemente, os fluxos de sentido, postos em circulação, são construídos e disputados por múltiplos atores sociais, pois são propositores/criadores da/na construção da realidade social, 
por meio dos processos comunicacionais. Logo, conduz aos atores das organizações reconhecerem a alteridade; seja na construção da figura modal do outro, seja na construção da situação de referência; ou, ainda, seja na alteridade constituída nas situações de parceiro-sujeito no processo. Já que, na atual conjuntura da sociedade midiatizada, a busca pelo reconhecimento de si por outro requer que este outro seja reconhecido igualmente. Essa dinâmica demostra o quão complexos podem ser os processos comunicacionais entre os múltiplos atores sociais. Este enfoque leva em consideração a ordem da reciprocidade e do antagonismo, uma vez que essa busca por visibilidade e legitimidade é estendida aos demais múltiplos atores sociais, que se fazem presentes nos ambientes digitais e as pleiteiam também. Podendo, assim, reorganizar as relações/vínculos frente às organizações.

Aspecto político: ocorre por meio da ética desdobrada no processo de legitimação, pois este processo se dá por meio do "explicar/justificar" ao outro, logo está contido na ética e, esta, no âmbito político, uma vez que, se concretiza nos relacionamentos e vínculos, que neste contexto, se materializa na estética; isto é, no discurso desdobrado por meio dos processos comunicacionais sócio-técnico-discursivos. Essas observações nos inserem no reconhecimento intersubjetivo (validade do discurso) nos relacionamentos/vínculos organizados por discursos sociais nos ambientes digitais, onde a identificação e a diferenciação tornam-se atuantes. Implica no "habitar" das organizações nos ambientes digitais como extensão e conexões; contudo, também implica na imagem moral das organizações construída pelos seus discursos públicos (SODRÉ, 2009). Portanto, sugere que as organizações além de "falar" de si mesmas, reconheçam o valor social do outro, isto é, reconheçam a alteridade como ator nos seus processos comunicacionais.

Matéria-prima: como o contexto da sociedade midiatizada requer que tanto as organizações como os múltiplos atores tenham suas subjetividades exteriorizadas por meio de processos comunicacionais. Logo, deixam dados, que ativam e organizam esses processos, que implicam na exposição de si ao "olhar" do outro, como também no "olhar" dos buscadores; logo emboca na matéria-prima informação ao qualificar estes dados (com significados e utilidades) e, assim, arrematando, na matéria-prima, conhecimento. Portanto, os elementos comuns às bases de poder que organizam os processos perpassam pelas matérias-primas: dados, informações e conhecimentos. Porquanto, os processos comunicacionais, ao serem pensados como relações/vínculos, ou seja, atos políticos, requerem que os dados, 
informações e conhecimentos sejam as matérias-primas das relações públicas, uma vez que o fenômeno da midiatização nos insere na esfera sócio-técnica-discursiva.

O lócus da função e da atividade: se dá através dos processos comunicacionais (sócio-técnico-discursivos) por meio dos ambientes digitais, que são encarados, nessa perspectiva, como ambiências e não meros instrumentos e/ou técnicas. Os ambientes digitais, então, são compreendidos como uma espécie de "extensão especular" da organização, na qual ela passa a "habitar" e, assim, "entra" e se "move" de acordo com os códigos e regras próprias a cada ambiente. Deste modo, implica no sentido ético-político do bem-comum, consequentemente a exteriorização da subjetividade que se dá por meio dos processos comunicacionais, que são acionados a partir das práticas tecnológicas do discurso, implicado em retórica e, esta, em elocução, linguagem, discurso, que atrelados com e nos ambientes digitais vão para além do processo de interação. Assim, a perspectiva acerca dos ambientes digitais pressupõe na refiguração das experiências tanto das organizações como dos múltiplos atores em seus relacionamentos e/ou vínculos, logo na refiguração do lócus da função e atividade das relações públicas.

Objetivo da função e da atividade de relações públicas: se dá na busca pelo institucionalizar (comunicar e fazer reconhecer) a organização como referência. E, para tanto, implica no explicar e justificar acerca do fazer e do existir da organização por meio de sua representação nos ambientes digitais e, a partir, do saber dizer/publicizar implicado nos processos comunicacionais que reconheçam e negociam com a alteridade.

Bases filosóficas: é apreendida por meio da intersecção entre ética e estética; ou seja, o processo de legitimação por meio dos processos comunicacionais nos/pelos ambientes digitais. Pois, ao adentrarmos na esfera da legitimidade atrelada à ética neste contexto, tem-se que, esta última, encontra-se vinculada à atitude ético-política, ao implicar em valores acoplados a diversos modos de apropriação social da transcendência valorativa. Assim sendo, a relação/vínculo encontra-se na exteriorização da organização, porém com obrigação para com o outro (reconhecimento do valor social do outro). Dessa forma, considera a premissa entre o limite de sua individualidade e o ato de se fazer sair de si mesmo e voltar-se para fora, para o outro.

\section{CONCLUSÕES}

Esse rearranjo, concernente à práxis das relações públicas no contexto 
da sociedade midiatizada, significou falar sobre a experiência tanto da teoria como da prática das relações públicas; isto é, da rede teórica incorporada às tecnologias e relacionada com as transformações do fenômeno da midiatização. A atividade prática das relações públicas, portanto, está para algo mais do que a reprodução indiferente de gestos técnicos no quadro de uma práxis puramente mecânica. Assim, exprime transformação pelo profissional; isto é, uma prática sem automatismos e sim atividade transformadora, tanto do objeto como do profissional. Pois, os processos são opostos à pura e simples transmissão de dados e/ou informações.

Nessa conjuntura, requer do profissional de relações públicas a interpretação das estruturas culturais no quadro da circulação de informações, sem confiná-la somente à explicação de textos com vistas aos sentidos, mas ampliar para uma exploração do objeto (ambiente digital) que tem parte ativa no processo de conhecimento. Isso gera o pensamento a respeito da práxis das relações públicas, bem como do ensino no âmbito universitário teórico, articulado com a prática na esfera da tecnologia. Por conseguinte, permite (re)pensarmos o perfil do profissional de relações públicas, no contexto da sociedade midiatizada, a partir da proposta desta rede teórica que se encontra sustentada na ética (legitimação), na política (relação) e na estética (processo comunicacional).

\section{REFERÊNCIAS}

BALDISSERA, Rudimar. Comunicação organizacional na perspectiva da complexidade. Organicom, São Paulo, n.10/11, p. 115-20, 2009.

. Estratégia, comunicação e Relações Públicas. Anais do XXIV Congresso Brasileiro da Comunicação. Campo Grande /MS, Setembro de 2001. p. 1-11.

BARICHELLO, Eugenia Mariano da Rocha. Apontamentos sobre as estratégias de comunicação mediadas por computador nas organizações contemporâneas. In: KUNSCH, Margarida M. K. Comunicação organizacional: histórico, fundamentos e processos. Vol.1. São Paulo: Saraiva, 2009.

Barichello (2008)

BARICHELLO, Eugenia Mariano da Rocha. Apontamentos em torno da visibilidade e da lógica de legitimação das instituições na sociedade midiatizada. In: DUARTE, Maria Elizabeth Bastos; CASTRO, Maria Lilia Dias de. Em torno das mídias. Porto Alegre: Sulina, 2008. p. 237-49.

; LASTA, Elisangela. Desintermediação na sociedade midiatizada: Petrobras e suas práticas comunicacionais no blog corporativo Fatos e Dados. Chasqui - Revista Latinoamericana de Comunicação. n.112, dez., 2010. p. 75-80. 
CADERNOS DE COMUNICAÇÃO

UNIVERSIDADE FEDERAL DE SANTA MARIA

BERGER, Peter; LUCKMANN, Thomas. A construção social da realidade: tratado de sociologia do conhecimento. ed. 14. Petrópolis: Vozes, 1997.

BRUNO, Fernanda. Máquinas de ver, modos de ser: visibilidade e subjetividade nas novas tecnologias de informação e de comunicação. Revista FAMECOS, Porto Alegre, n. 24, p. $110-24$, jul. 2004.

FELIPINI, Dailton. Google top 10: como colocar seu blog na primeira página do Google. Rio de Janeiro: Brasport, 2010.

JOHNSON, Telma. Pesquisa social mediada por computador: questões, metodologias e técnicas qualitativas. Rio de Janeiro: E-papers, 2010.

KUNSCH, Margarida M. Krohiling. Panorama e perspectivas dos estudos de comunicação organizacional e relações públicas na América Latina. In: DRUETTA, César Bolaño, Delia Crovi; CIMADEVILLA, Gustavo. La contribución de América Latina al campo de la Comunicación: historia, enfoques teóricos, epistemológicos y tendencias de la investigación. Associação Latino Americana de Investigadores de Comunicação, 2014. p. 246-91.

. Percursos paradigmáticos e avanços epistemológicos nos estudos da comunicação organizacional In: KUNSCH, Margarida M. Krohiling (org.). Comunicação Organizacional: histórico, fundamentos e processos. Vol.. São Paulo: Saraiva, 2009. p. 63-90.

LASTA, Elisangela. A práxis reflexiva das relações públicas na sociedade midiatizada: mediação estratégica comunicacional nos blogs corporativos. Tese (Doutorado em Comunicação) - Programa de Pós-graduação em Comunicação, Universidade Federal de Santa Maria, Santa Maria, 2015.

LEMIEUX, Vicent; OUIMET, Mathieu. Análise estrutural das redes sociais. Lisboa: Instituto Piaget, 2004.

MOURA, Cláudia Peixoto de. Fragmentos da História do Ensino de Relações Públicas no Brasil. In: MOURA, Cláudia Peixoto de. História das relações públicas: fragmentos da memória de uma área. Porto Alegre: PUCRS, 2008. p. 688-94.

OLIVEIRA, José Palazzo Moreira de. Busca inteligente na Web: um guia para tornar sua busca na Web eficaz e rápida. Porto alegre: Instituto de informática - UFRGS, 2010.

PERUZZOLO, Adair Caetano. Elementos da semiótica da comunicação: quando aprender é fazer. Bauru/SP: EDUSC, 2004.

SIMÕES, Roberto Porto. Relações públicas e micropolítica. São Paulo: Summus, 2001. . Relações Públicas: função política. São Paulo: Summus, 1995.

SODRÉ, Muniz. Antropológica do espelho: uma teoria da comunicação linear e em rede. Petrópolis: Vozes, 2009.

VÁZQUEZ, Adolfo Sánchez. Filosofia da praxis. Rio de Janeiro: Paz e Terra, 1968.

VERÓN, Eliseo. Teoria da midiatização: uma perspectiva semioantropológica e algumas de suas consequências. Matrizes, São Paulo, nº 1, jan./jun., 2014. p. 13-9.

VIZER, Eduardo Andrés. A trama (in) visível da vida social: comunicação, sentido e realidade. Porto Alegre: Sulina, 2011. 


\section{Elisangela Lasta}

Graduação em Comunicação Social com habilitação em Relações Públicas, Mestrado e Doutorado em Comunicação pela UFSM. Docente do Departamento de Comunicação da UFRGS. Conselheira voluntária no CONRERP $/ 4^{\circ}$. E pesquisadora nos GPs: a) Comunicação Institucional e Organizacional e b) Práticas de RRPP em suportes midiáticos digitais/CNPq/ UFSM.

E-mail: elisangela.lasta@ufrgs.br 